\title{
Entre la oralidad y la escritura. La importancia de la música, danza y canto de los Andes coloniales como espacios de significación, poder y mestizajes en contextos de colonialidad
}

\author{
Between Oral and Written Expressions. The Importance of \\ Music, Dance and Singing in the Colonial Los Andes as \\ Loci of Significance, Power and "Mestizaje" in Contexts of \\ "Coloniality"
}

\author{
por \\ Simón Palominos Mandiola \\ Magister en Estudios Latinoamericanos, Universidad de Chile, Chile \\ simonpalominos@gmail.com
}

\begin{abstract}
El presente artículo analiza el desarrollo de procesos de mestizaje cultural a partir de las expresiones musicales andinas del período colonial. Esto, con el fin de abrir la dicotomía "tradicional" que opone escritura y oralidad como las formas características de representación de la realidad propias de europeos y nativos (respectivamente). De esta forma, se espera poder comprender a los grupos sociales insertos en el espacio social colonial no como elementos estáticos sino que como identidades dinámicas que articulan para su autoconstitución como sujetos elementos de diversos sistemas de representación y registro: oralidad, escritura, representación "plástica", y en este caso la música, cantos y bailes.

Palabras clave: mestizaje, colonialidad, música colonial, Códice Trujillo del Perú, Baltasar Jaime Martínez Compañón.

This article analyzes the development of processes of cultural "mestizaje" on the basis of the Andean musical expressions of the colonial period, from the sixteenth to the eighteenth centuries. It aims to introduce flexibility into the traditional dichotomy between written and oral expression as representations of reality made by Europeans on the one hand and by native Americans on the other. Thus the social groups belonging to the colonial social space are considered not as static elements, but as groups with a dynamic identity capable of bringing together diverse system of representation and registration. These embrace oral and written expressions along with visual representations as well as music, songs and dances.
\end{abstract}

Key words: mestizaje, coloniality, colonial music, Codex Trujillo del Perú, Baltasar Jaime Martínez Compañón.

\section{INTRODUCGIÓN: COLONIALIDAD Y ENCUENTRO DE EPISTEMES}

No es nueva la idea de que el descubrimiento y conquista de América en su desarrollo histórico es un proceso complejo en el que la materialidad de la dominación 
político-militar no es sino que solo una arista (probablemente la más evidente y denunciada) de una multiplicidad de dimensiones de la vida social -como son a modo de ejemplo el aspecto económico y el ámbito cultural. Lo cierto es que a partir de la coyuntura de la conquista se delinea un nuevo espacio social cuya primera característica, según nuestro parecer, es el punto obvio de que el contacto entre conquistadores y nativos se inscribe en relaciones de poder coloniales. Estas funcionan mediante una oposición social fundamental entre dominadores/ conquistados, vale decir, entre españoles y nativos (sin excluir que otros grupos sociales serán subsumidos en la posición estructural subalterna; como es el caso de mujeres y niños), donde la copresencia de ambos grupos se desarrolla como relación de dominio.

La inserción de las relaciones entre los grupos sociales a un nuevo espacio social definido por la colonialidad ${ }^{1}$ opera a partir de la instauración de la hegemonía del grupo dominante por medio de la colonización de las diversas dimensiones de la vida social. En efecto, la empresa de conquista no hubiese sido posible si no es también por el desarrollo de batallas a nivel cultural como el conflicto entre sistemas de representación, lenguajes y soportes de registro propios de los espacios europeos o nativos ${ }^{2}$.

Pero hay algo sustantivo, de gran riqueza, que se esconde en el carácter evidente de la noción del encuentro, del contacto y de la colonialidad. Nos referimos al momento fundacional de la heterogeneidad que caracterizará la cultura latinoamericana ${ }^{3}$, como juego de identidades, sincretismos e hibridaciones, y que persiste incluso bajo la imposición de una pretendida unidad nacional bajo banderas republicanas. El contacto de culturas nativas y europeas pone en juego diversos sistemas de significación, conocimiento e interpretación de la experiencia. A partir de lo anterior, podemos afirmar que el contacto de culturas es ciertamente un encuentro de epistemes, de formas de conocimiento que dan sentido a la realidad de los distintos grupos sociales.

No obstante lo anterior, es necesario considerar que la constitución de la heterogeneidad cultural se encuentra inserta en los límites definidos por la colonialidad. El encuentro epistemológico es en gran medida una constante batalla por la imposición de formas de concebir el mundo, de sistemas de representación

1 Para los fines del presente artículo la noción de colonialidad se refiere a los mecanismos epistemológicos que permiten construir y sostener relaciones de poder cognitivo, representacional y experiencial que tienen lugar a partir del encuentro entre conquistadores europeos y nativos (Quijano 1992: 438). Estas relaciones de poder son constitutivas y simultáneas a la instalación de jerarquías sociales a nivel local y global que subyacen bajo los fenómenos institucionales, jurídicos y políticos de dominación y explotación tradicionalmente conocidos como colonialismo (Quijano 2007: 93). El carácter epistémico de la colonialidad, en oposición analítica pero en complementariedad histórica con la dimensión jurídico-institucional contingente del colonialismo, constituye el terreno sobre el que se configura la modernidad eurocéntrica a nivel mundial. Esto permite comprender en qué medida dichas relaciones de poder simbólico continúan operando aún con posterioridad al término formal del colonialismo, como un fundamento de las clasificaciones y jerarquizaciones sociales del capitalismo global contemporáneo.

2 Garavaglia y Marchena 2005.

3 Cornejo Polar 2003. 
de la experiencia y de registro de las mismas, que cambiarán drásticamente el equilibrio de fuerzas entre los grupos sociales en disputa, a la vez que modificarán ineludiblemente la experiencia vital en América.

Estas transformaciones mutuas son propias de la constitución del espacio social colonial. Lo interesante es que con el desarrollo histórico del contacto en la colonialidad, los sujetos sociales progresivamente desarrollan (con mayor o menor grado de conciencia) estrategias para posicionarse estratificadamente en la jerarquía social a partir de la utilización de las herramientas interpretativas que circulan en la sociedad colonial.

Se trata, sin duda, de realidades distintas, inconmensurables, mundos de la vida que interpretan y dan sentido a las experiencias de pueblos que a partir de la coyuntura del descubrimiento comparten una historia común, trazando trayectorias culturales que por definición son híbridas ${ }^{4}$ y que brindan las bases para la construcción de una cultura nueva propia del nuevo espacio social. Así como la figura del mestizo representa la ineludible cercanía física de grupos hegemónicos y subalternos en la sociedad colonial, a nivel cultural el mestizaje operará construyendo una nueva episteme, con sus respectivos sistemas de representación y registro de la experiencia acerca de elementos tanto nativos como europeos (y también, hay que notarlo, africanos).

El presente trabajo tiene como propósito el analizar el desarrollo de procesos de mestizaje cultural a partir de las expresiones musicales andinas del período colonial. Esto, con el fin de abrir la dicotomía "tradicional" que opone escritura y oralidad como las formas características de representación de la realidad propias de europeos y nativos (respectivamente). De esta forma se espera poder comprender a los grupos sociales insertos en el espacio social colonial no como elementos estáticos sino que como identidades dinámicas que articulan para su autoconstitución como sujetos elementos de diversos sistemas de representación y registro: oralidad, escritura, representación "plástica”, y en este caso la música, danzas y bailes.

La hipótesis que subyace a lo largo del trabajo es la consideración de la música, canto y bailes como espacio(s) privilegiados de la representación de la experiencia (no diremos directamente sistema de registro, pues la expresión conlleva diversos niveles de profundidad que pueden devolvernos al maniqueísmo de la distinción oralidad/escritura ${ }^{5}$ ). En ellos podemos apreciar tanto los procesos hegemónicos

4 Cornejo Polar 1997.

5 A modo de ejemplo: ¿el carácter performativo de danzas, cantos y músicas es el registro en sí mismo; o lo es su fijación en un soporte material como el sistema de notación?; ¿máscaras y vestuarios pueden cumplir tal función?. En este sentido, es de interés lo planteado por Hennion respecto de la compleja, diversa e inevitable mediación que caracteriza a la música y su conocimiento. Se trata de un objeto probablemente inasible en sí mismo, por lo que su estudio requiere constantemente su fijación -y con ella, su institucionalización- en diversos niveles de registro y práctica (asumiendo provisoriamente la distinción entre ambos) que median entre sujeto y objeto de conocimiento. Se trata de una teoría de las mediaciones originada a partir de la sociología durkheimiana que pretende escapar a los solipsismos de la distinción sujeto/objeto con interesantes implicancias epistemológicas (Hennion 2002: 19). Por otra parte, no cabe duda de que todos los niveles de la mediación así entendida 
de establecimiento de relaciones de poder coloniales como a su vez la capacidad de apropiación y resignificación de registros y prácticas que ocurren en la totalidad del cuerpo social. A diferencia de la clara identificación de los binomios letra/poder y oralidad/subordinación de la literatura colonial -en la música del período existirían mayores zonas difusas que dan pie a diferentes escenarios de la tensión entre poder y resignificación, dibujando un espacio situado entre la oralidad y la escritura-.

\section{EL ENCUENTRO EPISTEMOLÓGICO CON LA ALTERIDAD: DIFERANCIA Y MESTIZAJE}

La episteme europea puede entenderse como una matriz de conocimiento que funciona sobre la base de operaciones de traducción de lo desconocido a los propios términos, de manera de asegurar el control de lo diferente ${ }^{6}$. El encuentro de una humanidad que desafía el marco interpretativo de la episteme europea abre dentro de ella el espacio de definición de un otro, implicando a la vez la redefinición de sí misma en relación con él. Para la eficacia del establecimiento del control de la diferencia es necesario que en esta definición relacional "nosotros/ ellos" se introduzca una jerarquía de valores (o valoraciones, si se quiere). Estas se estructuran a partir de una serie de oposiciones binarias, como "adentro/ afuera", "superior/inferior", "bueno/malo", que con el desarrollo de las ciencias positivas en Europa se naturaliza y permite legitimar el dominio del otro. En este caso la más perdurable oposición quizás corresponda a la distinción "civilización/ barbarie"7, que establece un límite de humanidad alrededor del polo de lo europeo -deshumanizando todo lo que es concebido como bárbaro-.

Sin embargo, el juego de distinciones que opera desde la hegemonía de la episteme europea en su proceso de incorporación en suelo americano no ingresa como una resolución inmediata (si es que es posible hablar de alguna resolución). Lo que subyace es, siguiendo a Derrida ${ }^{8}$, la instauración de una diferancia fundamental que da sentido y determina el juego de encuentros e intercambios culturales entre las epistemes de conquistadores y nativos ${ }^{9}$. Diferancia que estructura las diferencias

son necesarios para dar significación a las prácticas y registros musicales en el proceso comunicativo (Gruszczynska1995: 25).

6 Mignolo 1994. Esta idea, por cierto, tampoco presenta gran novedad. Ya en 1944 Adorno y Horkheimer describían de manera similar el desarrollo del conocimiento moderno (Adorno y Horkheimer 1987).

7 Pagden 1988.

8 Derrida 2003.

9 Optaremos por la traducción "diferancia" para referirnos al término différance acuñado en francés por Jacques Derrida y desarrollado en profundidad en su conferencia de 1968: "La différance" (Derrida 1972), según se propone en la traducción española de 1994 (segunda edición en 2003). En términos sintéticos, la diferancia es una provocativa intervención escritural -porque no es ni palabra ni concepto, precisa el autor (Derrida 2003: 39) - destinada a exhibir al oyente y al lector la mudez sepulcral de las diferencias de sentido que constituyen el fundamento de toda significación y su incorporación en un sistema de representación como la escritura. En efecto, différence-diferencia-y différance en francés son homófonas. La diferancia pone en escena (o en papel) una diferencia no presente que desborda 
de las culturas, ineludible toda vez que escapa al juego de la estructura misma (es decir, de la estructura de diferencias) abriendo rizomáticamente ${ }^{10}$ nuevos ejes de diferencias, las que funcionan como espacios de conflicto entre epistemes que operan en una condición de copresencia una con otra.

Siguiendo a Cornejo Polar ${ }^{11}$, la heterogeneidad se estructura como una copresencia de epistemes en un encuentro traducible casi como un "grado cero" de la memoria. Es posible pensar que las epistemes funcionan con una relativa autonomía y en permanente intercambio a lo largo del proceso histórico de la conquista de América, cada una desarrollándose a la par y por medio del contacto entre las materialidades y tecnologías de la representación propias de cada una. Por ende, podemos concebir intercambios y permanencias entre, por ejemplo, distintos registros de las formas de conocimiento en funcionamiento, lo que abre el espacio a la existencia de memorias sociales paralelas, que circulan en sus propios campos lingüísticos y asociados a sus propios soportes. Ejemplos de ello lo constituyen las distintas interpretaciones del Diálogo de Cajamarca descrito por Cornejo Polar, donde tanto la escritura -ligada a lo europeo- así como la teatralidad -como registro de la memoria nativa- plantean desenlaces distintos de un mismo "hecho", o bien la pervivencia de sistemas de registro alternativos como los queros andinos descritos por Cummins ${ }^{12}$.

En este punto es preciso introducir un giro conceptual que permita dar cuenta del desarrollo histórico de la diferancia: nos referimos a la articulación entre procesos de significación y relaciones de poder. Si pensamos la cultura como el sistema de símbolos que entrega sentido a la realidad, debemos detenernos en la comprensión de los procesos de producción de los mismos. Desde un punto de vista estructuralista, la creación de significados no es un proceso espontáneo, sino que tiene directa relación con la estructuración relacional de los mismos a partir de la apertura del sistema de los signos a la dimensión diacrónica, vale decir, a la historia (el paso del sistema de la lengua a su actualización en el habla). Los procesos de significación entonces son "momentos" históricos en los que se actualizan significados en gran medida ya estructurados.

Respecto de este carácter estructurado es posible reinscribir el tema del poder (Weber, Marx: los sistemas simbólicos como instrumentos de dominación) y las relaciones con la estructura social (Durkheim: las estructuras simbólicas establecen

las posibilidades de representación, tematización y movilización. La diferancia viene a cuestionar la naturalización de las relaciones ontoteleológicas entre ser y habla reunidas artificiosamente en una lengua, recordando los límites del sentido expuestos (y simultáneamente ocultos) en el logocentrismo europeo (Espinoza 2006: 95). No es posible extendernos más aquí en las consideraciones filosóficas de la diferancia. Basta con indicar que su uso en el presente escrito permite explorar los procesos de invisibilización y mudez forzada que la episteme occidental busca imponer como formas de control de la otredad enfrentada en el descubrimiento, conquista y colonización de nuestra región; silencio que será cuestionado por la emergencia de la música, danza y canto en la América colonial.

10 Podríamos decir brevemente: sin determinismo causal, abierto al desarrollo de $n$ dimensiones, etc. - Deleuze y Guattari 2002.

11 Cornejo Polar 2003.

12 Cummins 2004. 
correspondencias con la estructura social). Aparece entonces la pregunta por las condiciones sociales de producción simbólica (cuyo objeto privilegiado es el lenguaje), es decir, de los procesos de significación y atribución de sentido. Esta preocupación por las condiciones sociales en las que se producen los fenómenos simbólicos permite dar cuenta de la emergencia de un campo cultural autónomo así como también de la concentración legitimada de la capacidad de producir símbolos en un determinado grupo social. Bajo esta perspectiva, tal privilegio social es naturalizado y se reproduce por medio de su cristalización en un lenguaje que generan por los grupos dominantes, el que funciona como un marco interpretativo de la realidad para los sectores subordinados dibujando un espacio hegemónico. Bourdieu ${ }^{13}$ dirá que mediante esta "alquimia simbólica" se reproduce el orden social, operando una verdadera violencia simbólica, ejercida con la anuencia de los dominados.

Bajo esta lógica podemos interpretar el desenvolvimiento del contacto de los sistemas de representación de europeos e indígenas, en tanto proceso mediante el cual se generan sustituciones, apropiaciones y resignificaciones. La empresa de la conquista entonces es inseparable de la conquista del espacio simbólico abierto en el encuentro epistémico, y puede apreciarse en la introducción de tecnologías de la representación (legitimadas en posición de superioridad por los conquistadores) que se oponen a las prácticas autóctonas. Todas estas prácticas conllevan el desarrollo de códigos, lenguajes, que permiten la interpretación y que se encuentran en un espacio de conflicto por la definición de lo interpretable y la legitimación de un determinado orden social. Se abre de esta manera un juego de oposiciones entre los distintos lenguajes, soportes y formas de lectura donde su distribución en un espacio hegemónico (y los márgenes del mismo) permite delinear el lugar de lo "colonial" como tropos de actualización de relaciones de poder ${ }^{14}$.

Es dable reconocer que la episteme europea opera por medio de la introducción de oposiciones fundamentales que reinscriben las diferentes prácticas y sus lenguajes de representación (que en el fondo, también son prácticas) en relaciones de poder. Los diferentes lenguajes se estructuran de manera jerárquica a partir de la definición constantemente actualizada por el conquistador "hegemónico" y por las posibles apropiaciones que tanto colonos así como nativos pueden realizar del repertorio de prácticas disponibles a partir de la situación colonial. Por lo demás, la estrategia de apropiación de determinado lenguaje (como tecnología de la representación) se corresponde con la posición de un determinado grupo en la jerarquía social, definida en este caso por la situación colonial. De esta manera,

13 Bourdieu 1997.

14 Entenderemos el vocablo griego tropos en un sentido literario, vale decir, como un espacio metonímico de significaciones en que una palabra o concepto desplaza el sentido naturalizado correspondiente a su uso habitual. En este trabajo, hablar de tropos nos permite indicar por ejemplo cómo lo "colonial" constituye un complejo entramado de relaciones de poder apoyado en y contestado por los distintos lenguajes, soportes y lecturas. Si bien en el campo de la música el uso del término tropo tiene significaciones específicas, considero posible advertir también el carácter de dinamismo simbólico que subyace en su uso. 
se constituye lo que Mignolo ${ }^{15}$ denominará locus de enunciación, el lugar desde el cual los sujetos elaboran interpretaciones legítimas -desde sus particulares locide la realidad.

Así, la oposición oralidad/escritura introducida desde el espacio hegemónico europeo, en la descripción realizada por Cornejo Polar ${ }^{16}$, es efectivamente un hecho de conquista y dominio (p. 32); en el que tras el principio de la unificación del lenguaje se esconde un afán de control social y administración de la diferencia ${ }^{17}$.

Es en este contexto en que se produce la construcción de un nuevo horizonte epistemológico a partir del encuentro entre conquistadores y nativos. Esta situación remite directamente a la construcción de una hegemonía propia de una situación de colonialidad. En efecto, se trata de la inscripción de la heterogeneidad en las relaciones de poder que estructuran las relaciones sociales. Apoyada por la materialidad de la conquista física y su manifestación en el orden simbólico de las representaciones, la episteme europea dibuja un "espacio colonial" al aspirar a imponer su sistema de interpretación del mundo en la experiencia del dominado. Sin embargo, como propondrá Williams ${ }^{18}$ desde los cultural studies británicos, la hegemonía es un proceso no totalizante, lo que abre el campo a un continuo espacio de luchas por la apropiación y resignificación de las tecnologías de la representación y sus códigos en juego. Esto, porque los espacios hegemónicos son un ámbito interpretativo de la realidad pero también de acción en ella, el que no obstante se encuentra necesariamente inserto en el contexto de relaciones de dominación y subordinación de unas clases respecto de otras. En este sentido, la hegemonía se constituye en un verdadero campo de lucha cultural entre los grupos hegemónicos y los subordinados. De esta forma, aplicando en otro contexto lo planteado por Hall ${ }^{19}$, se pueden apreciar lecturas negociadas o directamente contrahegemónicas apoyadas en la penetración y reapropiación por parte de los dominados de los símbolos propios de los núcleos de poder, como lo ejemplifica el caso de Guamán Poma de Ayala.

Pero ¿cómo caracterizar el desarrollo de esta multiplicidad de lecturas en un contexto de colonialidad? Para el abordaje de esta cuestión será de utilidad recurrir a un concepto particular de las relaciones coloniales entre europeos y nativos, el que tiene importantes proyecciones para el análisis de diversos contextos de contactos culturales: la noción de mestizaje.

El mestizaje es un fenómeno dotado de una extraordinaria complejidad, con implicancias en las diversas dimensiones de la vida social. En efecto, aun considerando el carácter biológico del hecho histórico de la mezcla de pueblos a partir de la situación colonial en América Latina, el concepto de mestizaje siempre ha estado cargado de importantes significaciones de carácter simbólico-cultural y

15 Mignolo 1994.

16 Cornejo Polar 2003.

17 Mignolo 1994.

18 Williams 1977.

19 Hall 2004. 
político. Permite designar tanto un determinado grupo social (el mestizo como categoría social) así como -por extensión- los procesos que le dan origen (el mestizaje propiamente tal).

Conviene instalar, en primer lugar, el mestizaje en el seno del desarrollo histórico de algunos conceptos que le son afines. Para Bernand ${ }^{20}$ el mestizaje y lo híbrido, si bien en principio designan fenómenos biológicos (la mezcla de razas, y la consecuente degradación de estas a raíz de la pérdida de su pureza -como el ejemplo de la estéril mula-), ya en la España medieval presentan delineado el carácter político de sus significaciones al orientarse a la denominación de la alteridad subordinada (a partir de la distinción español/moro). Este carácter político no debe perderse de vista, sobre todo cuando nos permite situar el mestizaje al interior de relaciones de poder; esto pues, como hemos dicho, la situación colonial se define por la relación fundamental dominador/dominado -españoles e indios ${ }^{21}$ - La instalación de esta distinción nos posibilita una definición más afinada de la idea de mestizaje: las mezclas no se dan en un espacio de horizontalidad simbólica, antes bien, están insertas en un marco general donde los elementos en juego se jerarquizan a partir de la hegemonía de un grupo social determinado que concentra la capacidad de hablar. Este grupo impone un marco interpretativo de la realidad que genera la situación de violencia simbólica ya descrita y reproduce la hegemonía del dominador.

Ciertamente, la reproducción por medio de los sistemas simbólicos de los espacios hegemónicos responde a la necesidad de instalar y mantener un orden, vale decir, un espacio de estabilidad que legitima y recrea el poder colonial, cristalizado en la figura político-jurídica de una sociedad estamental basada en una matriz simbólica de la pureza étnica de las castas ${ }^{22}$.

Sin embargo, la idea de un mundo ordenado se rompe al entrar desde los sujetos sociales, sobre todo aquellos situados fuera del espacio de la hegemonía. La distinción entre mestizaje y mestizo es problemática, ya que como formas de posicionamiento en un contexto de dominación son inseparables. El sujeto subalterno colonial no es homogéneo, sino que se define por la presencia de diversos grupos sociales que cuestionan la matriz originaria de la pureza (compuesta por españoles, indios, negros) que funciona a partir de la homogeneización y subordinación de la alteridad ${ }^{23}$. De esta forma, el mestizo como categoría social es la designación que aspira al control de la diferencia por parte de los espacios del poder. El mestizo es leído desde la hegemonía y del principio del orden como impureza, mezcla que transgrede el orden político, activando nuevos procesos de definición de espacios sociales a partir de una delimitación hegemónica de un adentro y un afuera ${ }^{24}$. La aspiración -propia de la episteme europea- al control de la diferencia, de la alteridad, origina lo que podemos llamar un paroxismo

\footnotetext{
20 Bernand 2001.

21 Silverblatt 2005.

22 Bernand 2001.

23 Silverblatt 1992.

24 Vinson III 2005.
} 
léxico, una multiplicidad de nombres para lo mestizo, en virtud del afán clasificatorio, con diversos niveles de eficiencia práctica ${ }^{25}$, cuyo principal ejemplo son las definiciones y representaciones gráficas de los cuadros de castas.

El mestizo, entonces, parece subvertir el orden moviéndose en las identidades. No obstante, el espacio de lo limítrofe deja de ser un "no lugar" si abandonamos la matriz dominante. El mestizo, por tanto, si bien no es una identidad en términos esencialistas $^{26}$ ligados a la matriz de la pureza, tampoco habita un espacio completamente ajeno. El mestizaje genera las condiciones en las cuales son posibles las apropiaciones y el desarrollo de estrategias de posicionamiento por parte de los grupos subalternos en el entramado de poder colonial.

Tales condiciones se reunirán en la ciudad colonial, la que funciona como el nuevo espacio privilegiado de la nominación y representación de la alteridad. Así como la lógica del "sistema republicano dual" 27 es el correlato jurídico-territorial de la matriz de la pureza, la ciudad (y en específico, el mercado) emerge como el espacio de contacto ${ }^{28}$. La ciudad es el espacio de escenificación del mestizaje: nuevos espacios sociales (la ciudad colonial como experimento político-urbano deja de ser copia fiel de la ciudad europea) ${ }^{29}$ dan lugar a nuevos sujetos ${ }^{30}$.

Los nuevos escenarios establecen zonas de contacto ${ }^{31}$ en las que el mestizaje constituye el mecanismo de reconstitución del sentido de la vida, roto por el trauma de la conquista. El mestizo, entonces, construye un espacio existencialmente operativo que conecta las epistemes nativas y europeas, cumpliendo la función que Gruzinski denominará intermediación ${ }^{32}$, lo que reside en una frontera epistémica porosa, flexible, pero jerarquizada. De la misma forma en que el sujeto colonial subordinado no es homogéneo, tampoco lo son las estrategias desarrolladas por ellos: la posición de intermediario cultural no es uniforme, sino que se estratifica de acuerdo con su correspondencia con las distintas esferas sociales en las que el individuo y los grupos se desenvuelven ${ }^{33}$.

25 Estenssoro 2000.

26 Abandonamos toda definición esencialista de identidad y optamos por una de carácter relacional, que se construye con el devenir histórico del contacto entre grupos sociales.

27 Vinson III 2005.

28 Bernand y Gruzinski 1999; Garavaglia y Marchena 2005; Lockhart 2000.

29 Rama 2004.

30 La pregunta que emerge es la posible existencia de otros espacios en los que es posible rastrear el mestizaje. La apertura del concepto operada por Gruzinski (2000) puede llevar a identificar espacios geográficos alejados del centro urbano en el que operan diversos registros en donde dirigir la mirada, especialmente en el contexto contemporáneo de la globalización, con la eficiencia operativa de los medios de comunicación (entre otros factores) que aparentemente trivializan las distancias geográficas. Obviamente, el límite de esta observación tiene relación con el acceso a tales medios, el que se encuentra distribuido jerárquicamente dentro de los distintos grupos sociales y sus espacios geográficos.

31 Pratt 1997.

32 Gruzinski 2000: 48.

33 Ejemplos exitosos de mediación cultural son particularmente prolíficos en casos donde hay correspondencia entre espacios de poder. A modo de ejemplo, los primeros indígenas formados por los misioneros europeos eran los jóvenes descendientes de la nobleza nativa. Si bien esto se inscribe en el proceso de instalación de la hegemonía europea, a su vez entrega al indio las herramientas para la elaboración de estrategias de posicionamiento. 
El mediador ${ }^{34}$, por ende, se estructura en posiciones jerarquizadas a partir de su capacidad de negociar con el poder colonial, lo que implica a su vez no una relación pasiva como objeto de poder, sino la posibilidad de su autoconstitución como sujetos, paradójicamente mediante la inserción en la red de relaciones de poder coloniales. Un ejemplo interesante al respecto tiene que ver con la categoría de indio ${ }^{35}$, la que en una primera instancia es una imposición homogeneizadora de las diferencias por parte de los grupos hegemónicos -proceso que podríamos denominar construcción de identidades subalternas-. No obstante, pronto es apropiada por los mismos grupos categorizados como tales, siendo capaces de utilizar estratégicamente las posibles ventajas comparativas que tal condición podría traerles en términos jurídicos, políticos y económicos -momento que denominaremos como constitución de sujetos subalternos ${ }^{36}$.

En consecuencia, el mediador significa la posibilidad de apropiación de las materialidades, prácticas y símbolos de la vida social colonial y su resignificación por medio de la constitución de un locus de enunciación definido por su desterritorialización y posterior reinscripción respecto de la lectura hegemónica. El juego en el que se definen nuevas territorialidades y la autoconstitución de sujetos sociales permite pensar que si bien el progresivo empoderamiento de los sujetos subalternos desde el siglo XVI puede leerse como extensión de la modernidad en América ${ }^{37}$, se trata -no obstante- de una nueva lógica particular, una lógica moderna y mestiza.

\section{UN ESPACIO INTERMEDIO: MÚSICA, CANTOS Y DANZAS DE LOS ANDES COLONIALES COMO EJEMPLO DE MESTIZAJE EN LA COLONIALIDAD}

Existen algunos ejemplos célebres de sujetos que se situaron en el espacio intermedio delimitado por la copresencia, contacto e intercambios de la frontera entre las epistemes europeas y nativas. Un caso paradigmático es el del indio ladino, en quien si bien se reproduce en gran medida la hegemonía de un grupo social -la conquista no hubiese sido tan efectiva sin el apoyo de la mediación cultural efectuada por los indios bilingües ${ }^{38}$ - también se abre la oportunidad de inserción exitosa en la vida social colonial. En el área andina, Guamán Poma de Ayala e Inca Garcilaso de la Vega -con una posición privilegiada dentro de la estructura social colonial- pudieron valerse de la escritura europea como plataforma de denuncia y reivindicación del mundo indiano.

34 Debemos abandonar aquí la noción de mestizo debido a su inscripción en la realización histórica del sistema de castas; en su lugar preferimos el término mediador, basados en los planteamientos de Gruzinski, debido a que permite enfocarse analíticamente a los procesos de contacto en el ámbito cultural.

35 Silverblatt 1992.

36 La idea es establecer una diferencia entre la construcción (en este caso dirigida por los grupos hegemónicos) de una identidad y la constitución de un sujeto autodeterminado.

37 Urbano 1997.

38 Garavaglia y Marchena 2005; Gruzinski 2007. 
El contexto de unificación del lenguaje como forma de control social en el que se desarrolla el mestizaje permite apreciar cómo la escritura europea intenta sustituir un amplio espectro de sistemas de representación nativos, que contienen sus propios soportes específicos, como es el caso de las representaciones de glifos en Mesoamérica o los queros del área andina ${ }^{39}$. Otras veces, el apoyo a la dominación europea viene dado por la introducción de sistemas que descansan en prácticas arraigadas en la población colonizada, como por ejemplo, la situación de la música dentro del proyecto evangelizador.

En efecto, y a diferencia de la primacía que tiene la escritura en la episteme occidental, los distintos grupos subalternos de la sociedad colonial manejaron distintos registros que contienen los elementos interpretativos de su experiencia vital. Un rol de importancia lo cumplen la música, danza y cantos, ellos funcionan como verdaderas formas de la memoria operantes fuera del espacio de la hegemonía europea. Es posible examinar este proceso mediante la revisión de algunas características de las músicas, cantos y danzas nativas de la zona andina.

La característica fundamental es que estas tres manifestaciones (música, danzas y cantos), o más bien, su denominación como tales, corresponden a la lectura hegemónica eurocéntrica respecto de las manifestaciones sonoras y performativas andinas. Habría que decir, en rigor, que en la zona andina no existe la música así como la conocemos nosotros ${ }^{40}$, sino que se encuentra inserta en las prácticas ritualizadas de la vida social nativa. De esta forma, cantos, música y danzas nunca se encuentran absolutamente separados como manifestaciones autónomas, sino que en el contexto performativo siempre existen juntas.

Uno de los conceptos fundamentales de las sonoridades andinas es el de Taki (taqui, thaki), que según Grusczcynska ${ }^{41}$ designa la conjunción de baile, música y canto, ligada al ámbito ceremonial y ejercido por la nobleza, como el huari y el coyo. En consecuencia, no se trataría de música popular, como el harawi ${ }^{42}$-haravi, yaraví-, el haylli, o el cachwa ${ }^{43}$-cachua, cashua. No obstante, las investigaciones de Vreeland 44 indican que ya en el siglo XVIII existen diversos puntos de contacto entre las expresiones musicales "populares" y de la nobleza indiana, estableciendo correspondencias entre las danzas aquí enumeradas en los registros del siglo XVIII, de finales del siglo XIX y los contemporáneos.

Sin embargo, el concepto de taki no se agota aquí. Para Abercrombie el thaki constituye un verdadero vehículo de la memoria, el que funciona como técnica de producción de comunidad política así como una forma de poética que se funde

39 Gruzinski 2007; Cummins 2004.

40 Vale decir, como manifestación artística autonomizada en un campo cultural.

41 Grusczcynska 1995: 21.

42 Una definición de principios del siglo XVII del Haravi nos dice lo siguiente: "Cantares de hechos de otros o memoria de los amados ausentes y de amor y aficion y agora se ha recibido por cantares deuotos y espirituales". Diego González Holguín. Vocabvlario de la lengva general de todo el Perv llamada lengua Qquichua, o del Inca (1608). Citado en Stevenson 1976: 262.

$43 \mathrm{El}$ cachwa consiste en una danza en ronda, mientras que el haylli es un canto de victoria (militar). Junto con el yaraví perviven a lo largo del período colonial insertos en las festividades religiosas cristianas.

44 Vreeland 1998. 
con la historia. El thaki tiene la particularidad de poner en cuestión la distinción entre cultura oral y cultura escrita, toda vez que articula la capacidad de generar comunidad con el "registro" y reconstrucción de la memoria histórica de la misma (2006: 15). Como refiere Stevenson ${ }^{45}$, los takis fueron transmitidos a la nobleza incaica por los amautas en las escuelas instituidas por Inca Roca alrededor del año 1350 (yachaywasi). No existiendo sistemas de registro escriturales ${ }^{46}$, tanto keros, quipus así como takis utilizan mecanismos mnemotécnicos para representar y reactualizar la memoria. El taki, entonces, constituye una performativa poética de la memoria social de los incas.

En relación con los aspectos propiamente musicales de las manifestaciones sonoras del área andina prehispánica, las investigaciones arqueológicas y etnomusicológicas realizadas sobre la base de las colecciones de instrumentos existentes, las crónicas de relatores -indios, mestizos y españoles-, y el análisis de las prácticas que perviven hoy, indican que el sistema musical andino, si bien no desarrolló la polifonía, tiene un importante carácter melódico y rítmico. Tanto es así, que aunque no existen en los instrumentos sobrevivientes de los tiempos precolombinos intervalos de notas comunes en el sistema europeo, sí hay evidencias del conocimiento y construcción sistemática de intervalos microtonales que no son captables por la episteme musical europea ${ }^{47}$. Asimismo, la tesitura que prevalece entre los incas corresponde a los registros altos, lo que se manifiesta tanto en los instrumentos de las colecciones prehispánicas así como en los relatos de cronistas. En efecto, una de las casas de vírgenes consagradas al culto (acllas, "escogidas") está compuesta por las niñas más jóvenes (9 a 15 años) y estaban dedicadas al estudio de la flauta y canto (taquiacllas), para su ejecución en ceremonias y fiestas ligadas a la nobleza, favorecidas por sus voces infantiles. En virtud de ello, para Stevenson no es raro que los españoles al escuchar la música inca la considerasen aguda y estridente ${ }^{48}$.

Por otra parte, el carácter comunitario de la organización territorial-social de los incas (el ayllu) se refleja en la conformación de los conjuntos de instrumentistas. La mayoría de las instancias de interpretación musical son de carácter grupal (no existe el intérprete de música, canto o danza solista), abarcando números que van desde unos cuantos hasta cientos. Interesante es, de todas formas, la influencia del dualismo filosófico inca, ya que el número de los integrantes de los conjuntos suelen ser múltiplos de 2, 4 y 8 .

El repertorio musical prehispánico comenzó a sistematizarse a partir del reinado del noveno Inca Pachacuti, quien ordenó por primera vez a mediados del siglo XV la recolección de piezas organizadas para el recientemente instaurado culto al

45 Stevenson 1978: 275.

46 Esto es, en los términos occidentales de la fijación fonética del lenguaje.

47 Stevenson (1976: 253) establece analogías entre la existencia de microtonos que escapan al registro europeo y la fonetización de ciertas letras y palabras para el lenguaje de los conquistadores (en la lengua aymara la distinción fonética entre $i$ y $e$ es mínima comparada con el énfasis en la distinción entre $c$ y $c c$, o $t$ y $t t$; de forma similar en quechua existen importantes diferencias entre $q$ y $q q$ mientras que no conocieron la $b, d y$ y otros sonidos consonantes).

48 Stevenson 1976: 273. 
Sol ${ }^{49}$. Por esta razón los músicos suelen gozar de un alto prestigio social entre los incas. Una de las características más peculiares del repertorio prehispánico es que cada melodía es única y propia a cada evento y canto. No existía la costumbre de entonar distintos cantos con una misma melodía. Sin duda, esto tiene relación con el carácter semántico de los takis: cada elemento (música, canto y danza) forma parte de la unidad significante ${ }^{50}$.

Es en este contexto de prestigio de las manifestaciones sonoras en que se inserta la dominación colonial. En efecto, luego del contacto entre europeos y nativos los primeros se dan cuenta del arraigo de las prácticas musicales en la población andina. Los europeos promovieron entre los indígenas la adopción de la polifonía europea, y estos últimos se mostraron particularmente interesados y hábiles en la interpretación de instrumentos españoles. Franciscanos, dominicos, agustinos y jesuitas rápidamente vieron el potencial de esta característica para la instalación de la legitimidad del dominio europeo mediante la puesta en marcha de un proyecto evangelizador ${ }^{51}$. Gerónimo de Oré (en Símbolo Catholico Indiano, 1598) insiste en que a los indios deben enseñárseles canto llano y polifonía además del uso de flautas, trompetas y chirimías, porque "el estudio de toda esta música lleva a la conversión" 52 .

De esta manera se abre un nuevo campo semántico para los indios que dota de existencia fenomenológica a la autoridad cristiana como legitimación de la hegemonía europea. Rondón afirma que el aprovechamiento de la música como vehículo de conquista simbólica es propio del desarrollo de un espacio misional ${ }^{53}$, el que puede ser leído como un tropos privilegiado de dominación sobre poblaciones amerindias y afroamericanas.

Esto es en cierta forma intuido por las autoridades eclesiásticas de Lima. En los Concilios Provinciales de Lima (a lo largo del siglo XVI) se establecen nuevas normas al culto y la evangelización, sobre todo referentes al mundo indígena. En sus resoluciones se encuentra la promoción de la enseñanza formal vocal e instrumental a los indios de las misiones -III Concilio, 1567- además de la utilización del idioma nativo de estos para las labores de evangelización -II Concilio, 1552_54. Para impulsar la afluencia de los pueblos de indios a los espacios misionales, se les otorga privilegios económicos a los que se incorporen como músicos. Muchos aprenden armonía según los cánones europeos, e incluso se vuelven diestros en composición. Por otra parte, rápidamente adoptan los instrumentos europeos, adaptándolos a sus formas musicales y desarrollando técnicas de construcción propias.

49 Stevenson 1976: 275 .

50 En este punto consideraremos al taki como unidad significante, porque la exclusividad con la que cada melodía se relaciona con un canto y una danza impide considerar solamente a la melodía como portador del sentido (que es lo que hace Gruszczynska 1995), más allá del valor analítico que pueda tener la distinción.

51 Rondón 2006; Rondón y Vera 2008.

52 Stevenson 1976: 278-279.

53 Rondón 2006; Rondón y Vera 2008.

54 Stevenson 1976; Rondón 2006. 
De esta manera, los indígenas ingresan al mundo musical europeo logrando articular su tradición musical con el nuevo sistema de representación. Los jóvenes descendientes de la élite indígena ingresan a las instituciones educativas que los europeos instalan para su adoctrinamiento: cantar, leer y escribir constituyen el programa de enseñanza de los misioneros a los jóvenes indígenas, lo que -en efecto- los posiciona como mediadores culturales. Sin embargo, el proceso es ciertamente un poco más complejo. A partir de las recomendaciones del Concilio limeño las órdenes eclesiásticas en Tierra de Indias realizan importantes labores de estudio (de gran valor etnológico) respecto de sistemas y prácticas nativas, con el fin de posteriormente utilizar estos conocimientos en el desarrollo de estrategias de evangelización y control social. Desde este punto de vista, las órdenes mendicantes también funcionan como mediadores culturales, debido a que deben posicionarse en el espacio colonial por medio de la articulación de símbolos europeos y nativos.

$\mathrm{Al}$ respecto, se pueden señalar los siguientes dos ejemplos. El terciario franciscano Juan Pérez Bocanegra en 1631 publicó la primera pieza de polifonía vocal del Nuevo Mundo ${ }^{55}$, el Hanacpachap Cussicuinin; una oración traducida al quechua con música de autor desconocido, quien probablemente fue un indio o mestizo: otro mediador cultural. En 1777, en Münster, el jesuita Bernardo de Havestadt publicó Chiludúgú sive tractatus Linguae Chilensis, el que dentro de sus páginas contiene la adaptación a melodías europeas de canciones eclesiásticas con textos en la lengua mapudungun ("chilidúgú" según Havestadt), un producto de sus años de misionero en el territorio del sur de Chile ${ }^{56}$.

El mediador cultural, en consecuencia, más que limitarse a un sujeto o posición determinados, es una nube de posiciones en la estructura social; algunas con mayor correspondencia con la hegemonía, otras alejadas de ella, pero siempre manteniendo el contacto.

Por lo demás, no olvidemos que la instalación del espacio misional -como parte del proyecto de conquista simbólica de la episteme europea- remite necesariamente al control de la diferencia como relación de poder. En la primera mitad del siglo XVII el sacerdote jesuita Pablo Joseph de Arriaga ejemplifica el proceso de control de la circulación de símbolos de la alteridad: para él, toda manifestación musical indígena -incluso los instrumentos mismos- cargan con el error de la idolatría y han de ser extirpados. La prohibición impulsada por el arzobispo de Lima Pedro de Villagómez se basa en la acusación de Arriaga relativa a la práctica sincrética realizada por los indígenas y negros de adorar a sus "ídolos" tras el disfraz de la veneración cristiana. Por ello, si bien ha de enseñarse canto a los indios, no deben permitirse las manifestaciones tradicionales de los mismos ${ }^{57}$.

Asimismo, producto del énfasis puesto en el desarrollo de la música y a la par de las transformaciones demográficas de la población indígena se comienza a masificar el acceso a la formación y el ejercicio de las artes musicales. Un gran contingente de músicos de origen nativo (los grupos subalternos comienzan a

\footnotetext{
55 Stevenson 1976: 280-184.

$56 \mathrm{Al}$ respecto $c f$. Rondón 1997.

57 Stevenson 1976: 264.
} 
socializar el conocimiento musical entre sus pares) se benefician en términos de evasión de tributos. Esta situación eventualmente preocupó a las autoridades temporales y eclesiásticas, quienes comenzaron la restricción de las prácticas musicales de los grupos subordinados, con el fin de reincorporarlos a los limitados circuitos de circulación simbólica construidos para el dominado ${ }^{58}$.

Lo cierto es que ya en el siglo XVIII la sociedad colonial es de una gran complejidad y diversidad. Los sujetos se desplazan entre los intentos desde los espacios hegemónicos de restaurar el orden por medio de la instalación de una sociedad estamental (de dudosa eficiencia práctica en la vida social) y la legitimidad vital de la que gozan ciertas manifestaciones simbólicas de las clases subalternas. En efecto, negros e indios suelen participar en festividades civiles y eclesiásticas con su música, cantos y danzas, muchas veces con el beneplácito de las autoridades ${ }^{59}$. Ya a estas alturas es innegable el producto de los procesos de mestizaje cultural. En las distintas materialidades de las manifestaciones "musicales" subalternas es posible apreciar tantos elementos nativos, así como afroamericanos y-ciertamente- aquellos propios de la hegemonía europea ${ }^{60}$.

Un ejemplo privilegiado para observar estos procesos es el códice Trujillo del Perú ${ }^{61}$. Fue elaborado por Baltasar Jaime Martínez Compañón (1737-1797), obispo de la diócesis de Trujillo al norte del Perú a fines del siglo XVIII, a partir del viaje de reconocimiento del territorio bajo su tutela realizado durante la primera mitad de la década de $1780^{62}$. Martínez Compañón realizó una exhaustiva labor de registro geográfico, botánico, zoológico, urbano y social, en el que se destaca la elaboración de acuarelas que representan la estructura social de la época y determinadas prácticas culturales de los grupos retratados. De interés para nuestro trabajo serán la descripción visual y la transcripción musical de danzas y cantos practicados por mestizos, indios y afroamericanos ${ }^{63}$.

La misma trayectoria de vida de Martínez Compañón es interesante, toda vez que permite comprender el interés y el desarrollo de su investigación. En su juventud estudió filosofía y leyes en España y se ordenó sacerdote en 1761. Desarrolló una prolífica carrera académica, llegando a ser incluso consultor de la Inquisición. Tenía conocimientos musicales y en 1767 fue designado por Carlos III como chantre en la Catedral Metropolitana de Lima. Allí fue visitador general de cofradías, por lo que estaba habituado al contacto con las clases subalternas

58 Estenssoro 1997.

59 Estenssoro 1997.

60 Stevenson 1976: 290-291.

61 Martínez Compañón 1998.

62 Conviene recordar que si bien la región de Trujillo no se encuentra precisamente ubicada en los Andes sino más bien en el sector costero, el Perú colonial durante el período de elaboración del códice ya muestra un permanente contacto e intercambio entre los indios de la costa y la sierra, los esclavos africanos y los colonos españoles. El registro dejado por Martínez Compañón muestra la copresencia de elementos musicales del mundo andino, ya comentados en el texto, pero ahora insertos en la sociedad colonial.

63 Para Claro (1980) y Stevenson (1976) tales manifestaciones son de carácter propiamente popular, en el entendido de situarse fuera de las manifestaciones hegemónicas de, por ejemplo, la música militar y eclesiástica. 
y sus manifestaciones culturales. En 1779 toma posesión del cargo de Obispo de Trujillo, cargo que ocuparía hasta $1790^{64}$.

Una de sus primeras iniciativas fue la ejecución de un "Viaje Pastoral" (como lo denomina Pérez Ayala ${ }^{65}$ ), que le permitió conocer de la situación de la diócesis, el que fue de suma utilidad para desarrollar su ulterior labor administrativa ${ }^{66}$. El viaje se extendió hasta 1785 . Con los numerosos apuntes de su viaje Martínez Compañón pretendía elaborar una historia general del obispado de Trujillo; sin embargo las obligaciones de su labor y su mermada salud le impidieron concretarla. No obstante sí confeccionó nueve tomos de su obra, además de una gran cantidad de cajones con muestras botánicas, geológicas y artefactos indígenas.

Los nueve tomos existentes de la obra de Martínez Compañón consisten en mapas y acuarelas que describen el obispado. Lamentablemente, los textos escritos que debían acompañar las imágenes (si es que existieron algunos) se han perdido. La exhaustiva tarea de registro tiene relación con la formación en artes liberales del obispo, pero -y quizás de mayor interés para nosotros- es posible relacionarla con una política del saber colonial, en el sentido de que el afán taxonómico, de registro y clasificación (cada tomo es de un tópico distinto) permite reinscribir lo desconocido en la trama del poder colonial. Tal política y la elaboración de los cuadros de castas permitirían poner a Martínez Compañón al lado del virrey Amat como ejemplos del control de la alteridad.

De interés para nosotros son los registros del volumen II. En ellos figuran imágenes de los distintos grupos sociales de la vida colonial andina, además de manifestaciones culturales de los grupos subalternos ${ }^{67}$. Especial atención merecen cincuenta y cuatro imágenes (folios E.140-E.193), estampas que ilustran principalmente danzas de indios, españoles y negros, representando la disposición espacial, vestuario e instrumentos musicales utilizados, entre otros elementos. Asimismo, los folios E.176 al E.193 presentan textos de piezas musicales junto a su transcripción en notación musical europea. Se trata de dieciocho tonadas recogidas en diversas localidades del obispado de Trujillo, correspondientes a distintas danzas en las que participan diversos grupos sociales subalternos, y en las que se pueden apreciar distintos niveles de mestizaje cultural.

En primer lugar destacan las cachuas, danzas en ronda provenientes de tiempos prehispánicos y que, como ya se ha mencionado, en tiempos coloniales tienen un importante carácter popular. De inmediato en ellas es posible observar el carácter de las mezclas y su inscripción en la hegemonía. Están dedicadas al nacimiento de Cristo ("Allegro Cachua a Dúo y a quatro, con voces y Bajo al Nacimiento de

64 Pérez Ayala 1955.

65 Pérez Ayala 1955.

66 Entre sus obras como obispo destacan la construcción de iglesias, creación de curatos, administración del Tribunal de Justicia, creación de pueblos, construcción de caminos, acequias, seminarios y, de manera interesante, cuatro "casas de educación para indios" de ambos sexos ("escuelas de cholitos y cholitas”). Cf. Pérez Ayala 1955.

67 Para Stevenson, no hay dudas de que el origen de la música es la gente común (1976: 313). 
Christo Nuestro Señor”, folio E.176, y “Allegro Cachua a voz y Bajo Al Nacimiento de Christo Nuestro Señor”, folio E.177), reafirmando la instalación del espacio misional mencionado con anterioridad ${ }^{68}$. Por otra parte, el instrumental utilizado para la interpretación de las cachuas consiste en laúd, arpa, chirimías y quijadas de burro. La apropiación de instrumentos españoles (sobre todo los instrumentos de cuerda polifónicos ${ }^{69}$ ) y la convivencia con percusiones e instrumentos de viento nativos y africanos es una clara muestra del mestizaje cultural. Puede apreciarse desde el folio E.140 al E.175, que ilustran danzas y conjuntos de instrumentistas para las distintas manifestaciones sonoras y coreográficas contenidas en el Códice.

Llama asimismo la atención la existencia de una tonada ejecutada por la población negra de Trujillo: "Allegro tonada El Congo a voz y Bajo para baylar Cantando" (folio E.178), la que aborda la temática de la esclavitud en la población africana. Sin lugar a dudas aquí se cumple lo descrito por Salinas en relación con la música africana. Efectivamente, se trata de ritmos de la memoria ${ }^{70}$ en donde se reconstruye y moviliza la identidad de los grupos afroamericanos. Sobre la base de lo anterior, es posible considerar las sonoridades andinas como portadores de memoria mediante el examen de los nexos entre las tonadas "Allegro tonada El tupamaro, Caxamarca" (folio E.188), "Magestuoso Cachua la Despedida de Guamachuco" (folio E.191), "Allegro tonada la brugita para cantar de Guamachuco" (folio E.190) y "Andantino Tonada el Diamante, para baylar de Chachapoyas" (folio E.187). En estas tonadas es posible identificar analogías musicales y textuales que funcionarían como una relectura de la captura y muerte del Inca Atahualpa y a la vez como un ejemplo de la pervivencia de códigos andinos en un contexto colonial ${ }^{71}$.

Por otra parte, algunas tonadas representan espacios históricos locales y memorias ancestrales, como en el caso del "Magestuoso Bayle del Chimo A violin y Bajo” (folio E.180) y la “...Bajo y Tamboril para baylar cantando. Tonada del Chimo" (folio E.), relacionada con las pervivencias del grupo étnico chimú. Lo interesante es que ella se encuentra en lengua mochica (ya extinta), perteneciente al grupo étnico que residía en la zona norte de Perú incluso antes de la llegada de los chimú. Según Stevenson ${ }^{72}$ se trata del único registro original de la lengua, pues otros registros existentes son traducciones del español al mochica. Otras tonadas presentan tanto un carácter festivo como responsorial y se relacionan con situaciones de cortejo: "Allegro tonada la Donosa a voz y Bajo para bailar Cantando" -folio E.182-, "Andantino tonadilla, llámase el Palomo, del Pueblo de Lambayeque para cantar y bailar" -folio E.185. Finalmente, hay tonadas que presentan una clara influencia europea en su composición musical, debido al uso de modulaciones extrañas a los usos tradicionales indígenas y de temáticas propias

68 Rondón 2006; Rondón y Vera 2008.

69 Los instrumentos de cuerda polifónicos eran desconocidos en América prehispánica. La apropiación de la bandurria española dio origen al charango, instrumento propio de las sonoridades andinas.

70 Salinas 2000.

71 Palmiero 2011.

72 Stevenson 1976. 
de la música popular española. En efecto, "Andante Cachuyta de la montaña llamádase el vuen querer" (folio E.193) es, para Stevenson y Claro ${ }^{73}$ la pieza más hispanizada del repertorio.

En consecuencia, la revisión del Códice Trujillo del Perú nos permite apreciar la copresencia de manifestaciones simbólicas correspondientes a matrices epistémicas nativas, africanas y europeas. Los registros y los sujetos sociales que les movilizan están envueltos en procesos de mestizaje cultural, dando origen a nuevos símbolos y representaciones producto de los contactos entre los diferentes repertorios simbólicos y el desarrollo de estos intercambios a lo largo de los siglos. En este sentido, las músicas, cantos y danzas retratadas en el Códice parecen escapar a la dicotomía fundamental entre oralidad y escritura, permitiendo observar la emergencia de un espacio que posee a la vez elementos de registro escritural, visual, performativo y sonoro, que pone a la luz la relevancia de dichas manifestaciones para la comprensión de las culturas e identidades latinoamericanas.

\section{CONSIDERACIONES FINALES: MESTIZAJE Y PROYECCIÓN DE LO POPULAR}

¿Cuál es la lectura que podemos hacer del documento reseñado a partir del mestizaje cultural? Como ya se ha observado, la función de mediador cultural no descansa en un sujeto homogéneo. Antes bien, se trata de una jerarquización de posiciones y estrategias a partir de los núcleos hegemónicos/subalternos, que genera como resultado del proceso un espacio heterogéneo y, por definición, nuevo. En el caso de la obra de Martínez Compañón, se puede observar claramente esta jerarquía del espacio poroso de la frontera epistémica. Los sujetos retratados en el códice (en la sección musical) realizan una mediación cultural desde lo subalterno, al apropiarse de sistemas de representación hegemónicos y articularlos con sus formas de la memoria. Por su parte, el obispo de Trujillo realiza una operación de mediación cultural desde lo hegemónico, orientada a la reinscripción de las prácticas en el espacio de la colonialidad.

Un asunto de importancia tiene que ver con un sujeto que no es visibilizado: se trata del o la copista en terreno de las tonadas y, por extensión, también de el o la dibujante de las acuarelas. Stevenson y posteriormente Claro ${ }^{74}$ especulan que el copista podría ser Pedro José Solís, maestro de capilla de la catedral de Trujillo; sin embargo, nada se sabe con certeza. Existe, pues, la posibilidad de que se trate de una persona mestiza en el pleno sentido de la palabra. Ante esta posibilidad sin duda nos encontraríamos frente a uno de los sujetos más representativos de los procesos de mestizaje descritos en el presente documento. Sería miembro de un espacio fuera de lo hegemónico que logra insertarse en la sociedad colonial por medio del manejo de sistemas de registro múltiples, que le permiten comprender

73 Stevenson 1976 , Claro 1980.

74 Stevenson 1976, Claro 1980. 
manifestaciones subalternas y reinscribirlas en el espacio del poder. Sin duda, se trata de una hipótesis especulativa, pero que puede dar lugar a interesantes reflexiones respecto del papel de la inserción en las esferas hegemónicas y el posible empoderamiento de los grupos subordinados. Aun si se trata de Pedro José Solís, es innegable que su trabajo también consiste en un proceso de mediación y mestizaje, elaborado desde el espacio de las élites.

Sabemos que a partir de la segunda mitad del siglo XVIII -y a pesar de la importante presencia de las manifestaciones festivas de los grupos subalternos en la vida social colonial (fiestas civiles, religiosas y carnavales)- los procesos de modernización introducidos por las reformas borbónicas intensificaron los mecanismos de control de la diferencia dirigidos a los sectores populares, englobándolos bajo el concepto homogeneizador de "plebe". En este contexto se pusieron en marcha operaciones de control de las prácticas musicales subalternas, e incluso de circulación de los cuerpos, que redujeron la difusa legitimidad de las manifestaciones simbólicas de los grupos subordinados. Los procesos de modernización intentaron deshacerse de toda referencia cultural dirigida a la tradición colonial para facilitar una reinvención en términos racionales abstractos, que serán el fundamento político de la ulterior instalación de las repúblicas ${ }^{75}$. En este punto se produce el progresivo abandono de la matriz estamental de la pureza como fundamento jurídico-político y nos acercamos a la emergencia del pueblo como sujeto histórico.

Tal pueblo, a partir de la heterogeneidad cultural sublimada en un sujeto autoconstituido sobre la base de elementos indios, europeos y africanos sin duda hallará una proyección política en sus manifestaciones simbólicas, sobre todo en la primera mitad del siglo XX, donde la música es elemento de empoderamiento para los grupos subalternos.

El desafío que, consecuentemente, se dibuja tiene relación con la dilucidación de los espacios musicales populares que se abren a partir de la apropiación y síntesis de los sistemas musicales tanto nativos como europeos por parte de un sujeto que en términos relacionales puede identificarse como popular, vale decir, en oposición estructural al espacio hegemónico constituido por la élite colonizadora que concentra el poder ${ }^{76}$. El espacio musical "profano-popular", según Carpentier ${ }^{77}$, sería con propiedad el espacio de la heterogeneidad donde se reúnen las influencias de los pueblos de América Latina-Europa, África y América ${ }^{78}$, pues se constituye al margen del espacio hegemónico misional que funciona como legitimación de la conquista y la situación colonial. De esta forma, adquiere un nuevo sentido la afirmación de una América Latina y de una música latinoamericana heterogénea, híbrida y mestiza.

75 Estenssoro 1997.

76 Hall 1984; Gramsci 2004.

77 Carpentier 2004.

78 Devoto 2004; Locatelli 2004. 


\section{BIBLIOGRAFÍA}

Abercrombie, Thomas

2006 Caminos de la memoria y del poder. Etnografia e historia en una comunidad andina. La Paz/Lima: Instituto de Estudios Bolivianos - Instituto Francés de Estudios Andinos.

Adorno, Theodor W. y Max Horkheimer

1987 Dialéctica del Iluminismo. Buenos Aires: Editorial Sudamericana.

BERnAND, CARMEN

2001 "Mestizos, mulatos y ladinos en Hispanoamérica: un enfoque antropológico de un proceso histórico”, en Miguel León Portilla (coordinador). Motivos de la antropología americanista. Indagaciones en la diferencia. México: Fondo de Cultura Económica, pp. 105-133.

Bernard, Carmen y SERge Gruzinski

1999 Historia del Nuevo Mundo. Los mestizajes, 1550-1640. México: Fondo de Cultura Económica.

Bourdieu, Pierre

1997 Razones prácticas. Sobre la teoría de la acción. Barcelona: Editorial Anagrama.

Cánepa, Gisela

1998 "Los ch'unchuy las palla de Cajamarca en el ciclo de la representación de la muerte del Inca”, en Raúl Romero (editor). Música, danzas y máscaras en los Andes. Lima: Pontificia Universidad Católica del Perú, Instituto Riva-Agüero, pp. 139-178.

Carpentier, Alejo

2004 "América Latina en la confluencia de coordenadas históricas y su repercusión en la música”, en Isabel Aretz (relatora). América Latina en su música. México: Siglo XXI Editores - UNESCO, pp. 7-19.

Clararo, Samuel

1980 "Contribución musical del obispo Martínez Compañón en Trujillo, Perú, hacia fines del siglo XVIII", RMCh, XXXIV/149-150 (enero-junio), pp. 18-33.

Cornejo Polar, Antonio

1997 "Mestizaje e hibridez: los riesgos de las metáforas", Cuadernos de Literatura, № 6. La Paz: Universidad Mayor de San Andrés, pp. 5-12.

2003 Escribir en el aire. Ensayo sobre la heterogeneidad sociocultural en las literaturas andinas. Lima - Berkeley: Latinoamericana Editores/CELAC.

Cummins, Thomas

2004 Brindis con el Inca. La abstracción andina y las imágenes coloniales de los queros. Lima: Universidad Nacional Mayor de San Marcos - Universidad Mayor de San Andrés - Embajada de los Estados Unidos de América.

Deleuze, Gilles y Félix Guattari

2002 Mil mesetas. Capitalismo y esquizofrenia. Valencia: Pre-Textos.

DERRIDA, JACQUES

1972 Marges de la philosophie. París: Les Éditions de Minuit.

2003 Márgenes de la Filosofía. Carmen González Marín (traductora). Madrid: Cátedra. 
Devoto, Daniel

2004 "Expresiones musicales; sus relaciones y alcance en las clases sociales", en Isabel Aretz (relatora). América Latina en su música. México: Siglo XXI Editores - UNESCO, pp. 20-34.

EsPINOZA LOLAS, RicARDO

2006 "En torno a la différance y la déconstruction... una lectura de Derrida desde ciertas 'huellas' heideggerianas”, Ágora. Papeles de filosofía, volumen 25. Santiago de Compostela: Servicio de Publicaciones, Universidad de Santiago de Compostela, pp. 83-106.

EstensSORo, JUAN CARLOS

1996 "La plebe ilustrada: el pueblo en las fronteras de la razón", en Charles Walker (compilador). Entre la retórica y la insurgencia: las ideas y los movimientos sociales en los Andes, siglo XVIII. Cusco: Centro de Estudios Regionales Andinos "Bartolomé de las Casas", pp. 33-36.

1997 "Modernismo, estética, música y fiesta: élites y cambio de actitud frente a la cultura popular. Perú 1750-1850”, en Henrique Urbano (editor). Tradición y modernidad en los Andes. Cusco: Centro de Estudios Regionales Andinos "Bartolomé de las Casas", pp. 181-196.

2000 "Los colores de la plebe: razón y mestizaje en el Perú colonial", en Los colores del mestizaje del virrey Amat. La representación etnográfica en el Perú colonial. Lima: Museo de Arte de Lima, pp. 67-107.

Garavaglia, Juan Carlos y Juan Marchena

2005 América Latina de los orígenes a la Independencia. Volumen II. La sociedad colonial ibérica en el siglo XVIII. Barcelona: Crítica.

Gramsci, Antonio

2004 Antología (selección de Manuel Sacristán). Buenos Aires: Siglo XXI Editores.

Gruszczynska, AnNA

1995 El poder del sonido: El papel de las crónicas españolas en la etnomusicología andina. Quito: Ediciones Abya-Yala.

GRUZINSKI, SERGE

2000 El pensamiento mestizo. Barcelona: Paidós.

2007 La colonización de lo imaginario: sociedades indígenas y occidentalización en el México español. Siglos XVI-XVIII. México: Fondo de Cultura Económica.

Hall, Stuart

1984 "Notas sobre la deconstrucción de lo popular", en Samuel Ralph (editor). Historia popular y teoría socialista. Barcelona: Crítica, pp. 93-112.

2004 "Codificación y descodificación en el discurso televisivo", Cuadernos de Información y Comunicación, N $^{\circ}$ 9. Madrid: Universidad Complutense de Madrid, pp. 210-236.

Hennion, Antoine

2002 La pasión musical. Barcelona: Paidós.

Locatelli de Pérgamo, Ana María

2004 "Raíces musicales", en Isabel Aretz (relatora). América Latina en su música. México: Siglo XXI Editores - UNESCO, pp. 35-52. 
LOCKHART, JAMES

2000 "La formación de la sociedad hispanoamericana", en Frank Moya Pons y Franklin Pease García-Yrigoyen (editores). Historia general de América Latina. Volumen II. Madrid: UNESCO/ Editorial Trotta, pp. 343-372.

Martínez Compañón, Baltasar Jaime

1998 Trujillo del Perú. Madrid: Agencia Española de Cooperación Internacional.

Martínez Miura, EnriQue

2004 La música precolombina. Un debate cultural después de 1492. Barcelona: Paidós.

Mignolo, Walter

1994 The Darker Side of the Renaissance. Ann Harbor: Michigan University Press.

Pagden, Anthony

1988 La caída del hombre natural. Madrid: Alianza.

Palmiero, Tiziana

2011 "Tupamaro de Caxamarca: tonadas sobre la muerte del Inca Atahualpa contenidas en el códice Martínez Compañón”, RMCh, LXV/216 (julio-diciembre), pp. 8-33.

Pérez Ayala, José Manuel

1955 Baltasar Jaime Martínez Compañón y Bujanda: prelado español de Colombia y el Perú. 1737-1797. Bogotá: Imprenta Nacional.

Pratt, Mary Louise

1997 Ojos imperiales. Buenos Aires: Universidad Nacional de Quilmas.

QujJano, Aníbal

1992 "Colonialidad y modernidad/racionalidad", en Heraclio Bonilla (compilador). Los conquistados. 1492 y la población indígena de las Américas. Quito-Bogotá: FLACSO, Tercer Mundo Editores, Ediciones Libri Mundi, pp. 437-448.

2007 "Colonialidad del poder y clasificación social”, en Santiago Castro-Gómezy Ramón Grosfoguel (editores). El giro decolonial. Reflexiones para una diversidad epistémica más allá del capitalismo global. Bogotá: Siglo del Hombre Editores; Universidad Central, Instituto de Estudios Sociales Contemporáneos y Pontificia Universidad Javeriana, Instituto Pensar, pp. 93-126.

ROMERO, RAÚL

1998 "Cambio musical y resistencia cultural en los Andes centrales del Perú", en Raúl Romero (editor). Música, danzas y máscaras en los Andes. Lima: Pontificia Universidad Católica del Perú, Instituto Riva-Agüero, pp. 21-60.

RONDÓN, VÍCTOR

199719 canciones misionales en mapudúngún contenidas en el Chilidúgú (1777) del misionero jesuita, en la Araucanía, Bernardo de Havestadt (1714-1781). Santiago: Revista Musical Chilena, Fondo de Desarrollo de la Cultura y las Artes (FONDART) y Chimuchina Records.

2006 "Sung Catechism and College Opera: Two Musical Genres in the Jesuit Evangelization of Colonial Chile", en John W. Malley y otros (editores). The Jesuits II. Cultures, Sciences, and the Arts. 1540-1773. Toronto: University of Toronto Press, pp. 498-510.

Rondón, Víctor y Alejandro Vera

2008 "A propósito de nuevos sonidos para nuevos reinos: prescripciones y prácticas músico-rituales en el área sur andina colonial”, Latin American Music Review, XXIX/2, (otoño-invierno), pp. 190-231. 
Salinas, Maximiliano

2000 “Toquen flautas y tambores!: una historia social de la música desde las culturas populares en Chile, siglos XVI-XX”, RMCh, LIV/193 (enero-junio), pp. 45-82.

Silverblatt, Irene

1992 "El surgimiento de la indianidad en los Andes del Perú central: el nativismo del siglo XVII y los muchos significados de 'indio'”, en Gary H. Gossen, Jorge Klor de Alva, Manuel Gutiérrez y Miguel León-Portilla (editores.). De palabra y obra en el nuevo mundo. Volumen tres. La formación del otro. Madrid: Siglo XXI, pp. 459-482.

\section{STEvenson, Robert}

1976 Music in Aztec \& Inca Territory. Berkeley y Los Angeles: University of California Press, California Library Reprint Series Edition.

URBANO, HENRIQUE

1997 "Introducción: la tradición andina o el recuerdo del futuro", en Henrique Urbano (editor). Tradición y modernidad en los Andes. Cusco: Centro de Estudios Regionales Andinos "Bartolomé de las Casas", pp. VII-L.

VREELAND, JAMES JR.

1998 "Danzas tradicionales de la sierra de Lambayeque", en Raúl Romero (editor). Música, danzas y máscaras en los Andes. Lima: Pontificia Universidad Católica del Perú, Instituto Riva-Agüero, pp. 179-217.

VINSON III, BEN

2005 "Estudiando las razas desde la periferia: las castas olvidadas del sistema colonial mexicano (lobos, moriscos, coyotes, moros y chinos)", en Juan Manuel de la Serna (coordinador). Pautas de convivencia étnica en la América Latina Colonial. México: Universidad Autónoma de México (UNAM), pp. 247-307.

Williams, RAYMOND

1977 Marxism and literature. Oxford: Oxford University Press. 